\title{
GEOBIM BENCHMARK 2019: INTERMEDIATE RESULTS
}

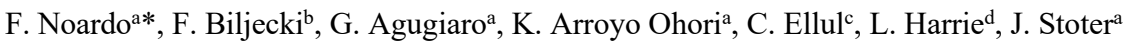 \\ a 3D Geoinformation group, Delft University of Technology, Delft, The Netherlands - (F.Noardo, G.Agugiaro, \\ G.A.K.ArroyoOhori, J.E.Stoter)@tudelft.nl \\ b Department of Architecture, National University of Singapore, Singapore - filip@nus.edu.sg \\ ${ }^{\mathrm{c}}$ Department of Civil, Environmental and Geomatic Engineering, University College London, London, UK - c.ellul@ucl.ac.uk \\ ${ }^{\mathrm{d}}$ Department of Physical Geography, Lund University, Lund, Sweden - lars.harrie@,nateko.lu.se
}

KEY WORDS: GeoBIM, software support, data interoperability, open standards, CityGML, IFC, 3D city models, BIM.

\begin{abstract}
:
An investigation into the implementation state of open standards in software is currently ongoing through the ISPRS/EuroSDR 'GeoBIM benchmark 2019' initiative, which kicked off earlier this year. The benchmark activity provides a way of assessing and comparing the functionality of different software packages in GIS and BIM in terms of their ability to handle standardised data (IFC and CityGML) and undertake various tasks using this data. Approximately 65 people have registered to participate so far, with participants from a wide range of backgrounds and proposing to test a variety of software packages. This confirms that the issues under investigation are of interest, and also meets the wider benchmark aim of having a variety of participants, since the project is conceived as using a bottom-up approach with cross-disciplinary and cross-expertise participation. While full benchmark results are not due to be submitted until later this year, interim results have highlighted a number of common issues across multiple software packages, and a web meeting for participants held in July 2019 also led to some improvements in how the benchmark results are being captured.
\end{abstract}

\section{INTRODUCTION}

Many applications dealing with urban analyses and management can be supported effectively by 3D models. Thorough overviews can be found in Biljecki et al. (2015), McGlinn et al. (2016), and Wu et al. (2018).

These applications are generally supported by two main sources of 3D data:

- 3D city models, stemming from the geospatial domain, which are used to represent city objects and succeed maps and other cartographic products in order to support city analysis and management, city planning, navigation, and so on.

- Building information models (BIM), from the architectural engineering and construction domain, which assist the building (and infrastructure, and any other construction) design and construction, and which also have features useful to project management and asset management.

Both domains have strong potential to capture valuable data about the built environment. However, the data in both domains have different characteristics, such as the kind of geometry which is used (mainly solid parametric objects in $\mathrm{BIM}$ and boundary representation of surfaces in $3 \mathrm{D}$ city models), the semantics used to structure their entities (e.g. specific materials for BIM and uses for 3D city models), and the need to georeference the models (essential in 3D city models and seldom carried out for BIM). The same characteristics are reflected in the respective open standards, which are used to archive their information in interoperable and open formats to represent and exchange, respectively, 3D city models and BIM models: CityGML by the Open Geospatial Consortium (OGC, 2012) and the Industry

\footnotetext{
$1 *$ Corresponding author

${ }^{2}$ https://3d.bk.tudelft.nl/projects/eurosdr-geobim/
}

Foundation Classes (IFC) by buildingSMART (ISO16739:2013) are well-known standards used in most cases.

The integration of both models, often known as 'GeoBIM', is receiving a lot of interest by many stakeholders (researchers, software companies, National Mapping and Cadastral Agencies, city administrators, practitioners). The aim is the lossless exchange of information between geospatial (3D city models) and BIM sources (Ellul et al., 2018), in order to enable the reciprocal enrichment of the two kinds of information, with advantages for both fields (e.g. automatic updates of 3D city models with high level-of-detail features, automatic representation of BIMs in their context, automated validation tests of the design against regulations, and so on). Much research is currently ongoing in this field (Liu et al., 2017, Zhu et al., 2018). However, the connection with the world of practice and the availability of mainstream technical solutions is still limited.

To address this challenge, a number of projects have been started to investigate the issue and fill the interoperability gap between Geo and BIM (e.g. Sani and Rahman, 2018; Wang et al., 2019; EuroSDR GeoBIM project ${ }^{2}$ ). In particular, the GeoBIM benchmark was funded as an ISPRS scientific initiative $^{3}$, and co-funded by EuroSDR, to test available software tools against their support of open standards.

This paper describes progress in the benchmark testing including intermediate results.

\subsection{The GeoBIM benchmark}

The GeoBIM benchmark is intended to link the expertise of many people with different skills, coming from different fields and with different interests, in order to provide a framework as complete as possible to describe the present ability of existing

\footnotetext{
${ }^{3}$ https://3d.bk.tudelft.nl/projects/geobim-benchmark/
} 
software tools to use (i.e. read, visualise, import, manage, analyse, export) CityGML and IFC models and understand their performance while doing so, both in terms of information management functionalities, and, eventually, information loss, and in terms of ability to handle large datasets.

Areas to be explored within this project include the issues related to current software and tools for effectively managing CityGML and IFC data. Such tools, when managing data using these standards, do not always effectively support features or functionality as they support when the data is held in the native formats of the software. In addition, the software tools have limits in the representation (geometry, semantics, georeferencing) of data structured in these standards, or can generate errors and wrong representations (e.g. Bazjanac, 2002).

The aim of the benchmark therefore is to get a better picture of the state of software support for the two open standards IFC and CityGML and their integration, in order to formulate recommendations for further development of the standards and the software that implements them.

For this purpose, a set of IFC and CityGML datasets are provided (Noardo et al., 2019) and used by external participants in the software they would like to test in order to check the support of it for open standards, following common instructions and providing results in a common template.

In particular, the four topics investigated in the benchmark are:

1. What is the support for IFC within BIM (and other) software?

2. What options for geo-referencing BIM data are available?

3. What is the support for CityGML within GIS (and other) tools?

4. What options for conversion (software and procedural) (both IFC to CityGML and CityGML to IFC) are available?

A parallel but not less important goal of the benchmark is to offer a common ground where people coming from various fields and having different interest can meet to tackle a common challenge, namely, the use of open standards for exchanging cross-discipline information and models.

\section{THE GEOBIM BENCHMARK MATERIALS AND METHODS}

\subsection{Developing the Benchmark Materials}

A number of datasets from different sources were identified and pre-prepared (and pre-processed) for this benchmark activity (see Noardo et al., 2019 for details). Table 1 summarizes the descriptions, features and aims of the provided datasets $^{4}$.

\begin{tabular}{|c|c|c|}
\hline \multicolumn{3}{|c|}{ IFC datasets } \\
\hline Name & Description & Aim \\
\hline Myran.ifc & $\begin{array}{l}\text { Model of a small 2-floor } \\
\text { building in Sweden, by } \\
\text { Swedish architects. } \\
\text { Georeferenced. IFC } \\
\text { v. } 2 \times 3\end{array}$ & $\begin{array}{l}\text { Test of the main } \\
\text { functionalities of } \\
\text { software and } \\
\text { common- } \\
\text { requirements } \\
\text { procedures. }\end{array}$ \\
\hline UpTown.ifc & $\begin{array}{l}\text { Model of a big complex } \\
\text { tower in Rotterdam, by } \\
\text { Dutch architects. IFC } \\
\text { v. } 2 \times 3\end{array}$ & $\begin{array}{l}\text { Test of the } \\
\text { hardware-and- } \\
\text { software } \\
\text { connected } \\
\text { performances. }\end{array}$ \\
\hline $\begin{array}{l}\text { Savigliano.if } \\
\text { c }\end{array}$ & $\begin{array}{l}\text { Model of a building in } \\
\text { Italy, by Italian architect } \\
\text { within research } \\
\text { environment. IFC v.4 }\end{array}$ & $\begin{array}{l}\text { Test of the } \\
\text { support for IFC } \\
\text { v. } 4 \text { and to enable } \\
\text { the tests of } \\
\text { procedures and } \\
\text { tools working } \\
\text { with IFC v.4 }\end{array}$ \\
\hline $\begin{array}{l}\text { Specific IFC } \\
\text { geometries }\end{array}$ & $\begin{array}{l}\text { Set of geometries } \\
\text { modelled using a range } \\
\text { of the modelling } \\
\text { alternatives allowed in } \\
\text { IFC, which are usually } \\
\text { little supported or } \\
\text { incorrectly interpreted by } \\
\text { software. Two versions } \\
\text { of the file are provided, } \\
\text { in IFC v.2x3 and IFC } \\
\text { v.4. }\end{array}$ & $\begin{array}{l}\text { Test of the } \\
\text { support and } \\
\text { behaviour of } \\
\text { software with } \\
\text { respect to these } \\
\text { specific } \\
\text { geometries. }\end{array}$ \\
\hline \multicolumn{3}{|c|}{ CityGML datasets } \\
\hline Name & Description & Aim \\
\hline $\begin{array}{l}\text { Amsterdam.g } \\
\mathrm{ml}\end{array}$ & $\begin{array}{l}\text { Seamless city model } \\
\text { covering the whole city } \\
\text { of Amsterdam, including } \\
\text { several CityGML city } \\
\text { entities (vegetation, } \\
\text { roads, water, buildings, } \\
\text { and so on). Level of } \\
\text { Detail (LoD)1. } \\
\text { Generated through } \\
\text { 3Dfier by TUDelft }\end{array}$ & $\begin{array}{l}\text { Test of the } \\
\text { hardware-and- } \\
\text { software } \\
\text { connected } \\
\text { performances (it } \\
\text { is a very heavy } \\
\text { model), and } \\
\text { support for the } \\
\text { included city } \\
\text { classes. }\end{array}$ \\
\hline $\begin{array}{l}\text { RotterdamLo } \\
\text { D12.gml }\end{array}$ & $\begin{array}{l}\text { Texturised CityGML } \\
\text { model of one district in } \\
\text { Rotterdam, including } \\
\text { only Buildings in LoDs } 1 \\
\text { and } 2 \text {. }\end{array}$ & $\begin{array}{l}\text { Test of the } \\
\text { support for } \\
\text { multiple LoDs } \\
\text { and texturised } \\
\text { files. }\end{array}$ \\
\hline $\begin{array}{l}\text { BuildingsLo } \\
\text { D3.gml }\end{array}$ & $\begin{array}{l}\text { Procedurally modelled } \\
\text { Buildings in LoD } 3 \\
\text { through Random3Dcity } \\
\text { (Biljecki et al., 2016). }\end{array}$ & $\begin{array}{l}\text { Test of the } \\
\text { support for LoD } \\
3 \text { files and related } \\
\text { classes. }\end{array}$ \\
\hline
\end{tabular}

Table 1 . Summary of the provided datasets for the tests.

\footnotetext{
${ }^{4}$ https://3d.bk.tudelft.nl/projects/geobim-benchmark/data.html

${ }^{5} \mathrm{https}: / /$ github.com/tudelft3d/3dfier
} 
In parallel with this task, in order to make the obtained results uniform, a results template was provided as online forms both giving detailed instructions to perform the tests and guiding the answering through specific questions. The aim of this approach is to ensure that the results can be systematically compared, and allows users to detail their experiences for each task, issues encountered and specific functionality offered (or not offered) by the tested software. Importantly, they can include screenshots to highlight specific results or challenges.

\subsection{Participant Recruitment}

To eliminate any bias in the results as much as possible, it is important to recruit participants from a wide variety of backgrounds, with different expertise (e.g. BIM, GIS and more) and with access to different software packages that can be tested. This will give a wide understanding of the available open and proprietary software and the strengths and limitations of each package.

Participants have been recruited as follows:

1. Via the mailing lists of ISPRS and EuroSDR as well as via national and international networks of the individual investigators and advisory board members (in the Netherlands, Sweden, Singapore, Greece, UK, Italy, EuroSDR network, including National Mapping and Cadastral Agencies, ISPRS, OGC, professional networks and so on);

2. Via the project website ${ }^{7}$, websites of involved research groups and social networks (ResearchGate, LinkedIn, Twitter, Facebook);

3. Via advertising during talks and communications at various conferences and meetings (e.g. ISPRS Geospatial Week 2019, GeoRes2019, FOSS4GNL conferences, EuroSDR and OGC meetings, presentations during activities within related projects, like the EuroSDR GeoBIM project)

4. Via personal invitation of developers and representatives of software companies.

5. Via introducing the GeoBIM topic within related University MSc courses and thesis topics to involve students.

From these initial networks, a snowballing effect has led to further interest.

\subsection{The GeoBIM benchmark (web)meeting}

To further strengthen this multi-sectoral collaboration, some open events were organised ${ }^{8}$, the first of which, the GeoBIM benchmark (web)meeting, was held on $8^{\text {th }}$ July 2019.

In the meeting, 14 people from different countries and affiliations participated, including Universities and research institutes, National Mapping and Cadastral Agencies, software companies and developers. All of them work or have an interest in the integration of 3D city models with BIMs.
After discussing some improvements to the provided materials to help the testers, the participants presented their experiences in performing the different tasks. The initial results discussed in Noardo et al. (2019) were confirmed: all participants found common issues such as error messages when importing IFC files (even if the software was able to open them), the difficulty for tools to manage large datasets (specifically, amsterdam.gml and UpTown.ifc), among others. Additional tests on the benchmark datasets were carried out by some participants, in order to have an external confirmation that the datasets can be used and will not affect the software test results.

\section{PROGRESS IN THE PARTICIPATION}

After some months from the beginning of the initiative, we have registered a growing interest in the initiative: at the time of writing (July 2019), there are approximately 100 followers around the world (Figure 1), including those participants (approximately 65) that are going to carry out the tests in the following months?.

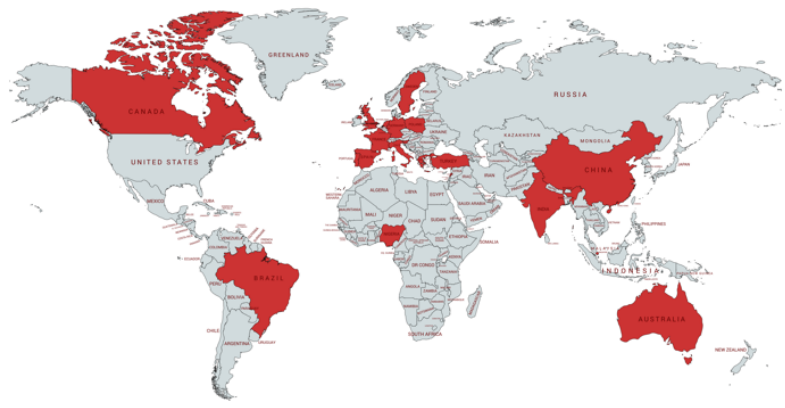

Figure 1. Map of countries of origin of the registered participants to the GeoBIM benchmark as of $15^{\text {th }}$ July 2019 .

It is interesting, and useful for raising the value of the final results, that participants come from different fields of expertise (Figure 2) and different affiliations (Figure 3), despite the higher number of researchers as well as participants from the geoinformation domain. It could be due to the fact that interoperability topics are stronger and rooted since longer times in the GIS domain than in the building information one.

In any case, this variety will help to actually join different interests and abilities in managing the data and exploiting the software complex potentialities to build a more complete framework. For example, different stakeholders could use the same software for different kinds of tasks in their work and, therefore, they could report on different functionalities.

Moreover, it will also allow the collection of comments and feedback that can be passed on to both software implementers and open standards developers. Compiling common experiences from different points of view will provide a clearer view of the steps that need to be taken to ensure that the promised higher levels of GeoBIM interoperability can actually be achieved in practice.

\footnotetext{
${ }^{7}$ https://3d.bk.tudelft.nl/projects/geobim-benchmark/

${ }^{8}$ https://3d.bk.tudelft.nl/projects/geobim-benchmark/events.html
} 


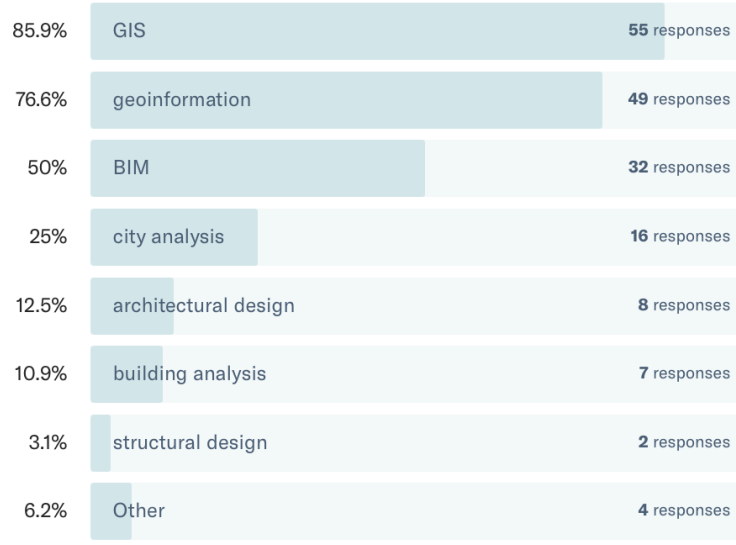

Figure 2. Main interests of the registered participants.

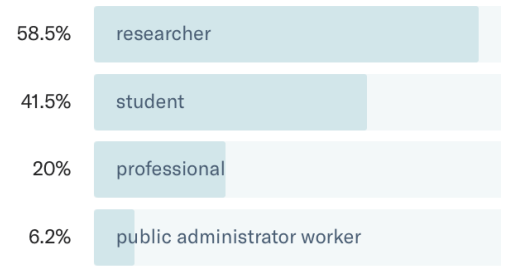

Figure 3. Kind of affiliation of the registered participants.

To better assess the results, a question in the results template asks explicitly for the level of expertise with the software they are testing, allowing values:

1 - Novice user (nearly the first time using the software)

2 - Regular user

3 - Expert user (knows very well technical details and less documented tricks)

4 - Developer of the tested software.

Submitted results are welcome, no matter what the level of expertise of the user is. However, it is useful to know what is the level of confidence of the tester with the tested software to allow for a more detailed set of evaluations: e.g. the userfriendliness of the tools; the actual potentialities with or without plugins and workarounds; to double check the validity of reported results. We have already noticed so far that the testers report the same issues (e.g. in Autodesk software) when having a different level of expertise (both 1 and 3), which is a good indicator of the replicability and validity of the test.

\section{PROGRESS OF SUBMITTED RESULTS}

There seems to be a rather balanced interest in carrying out the tests related to the four different tasks (Figure 4).

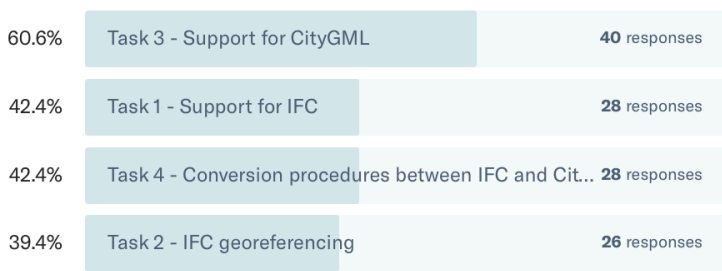

Figure 4. Registrations for performing each benchmark task.

For the moment, only a few of the registered participants have delivered the results (Figure 5). However, the list of software which participants declared their willingness to test in the registration form covers already a rather wide spectrum of the available solutions (Figure 6). After the deadline, some tools not yet considered will be tested by the project team, to fill the main gaps. Other tests might have been done to replicate contradictory results.

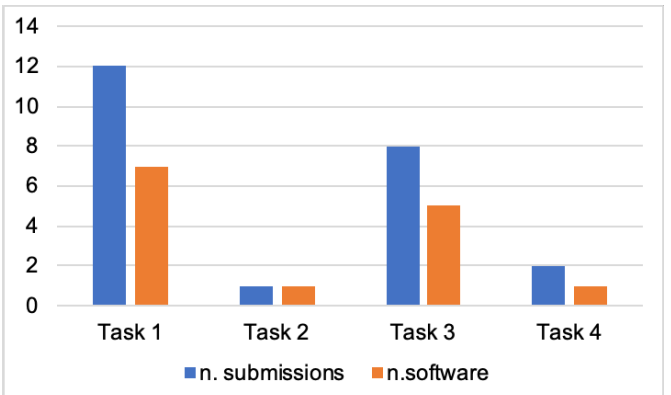

Figure 5. Comparison between number of tests and tested software per task.

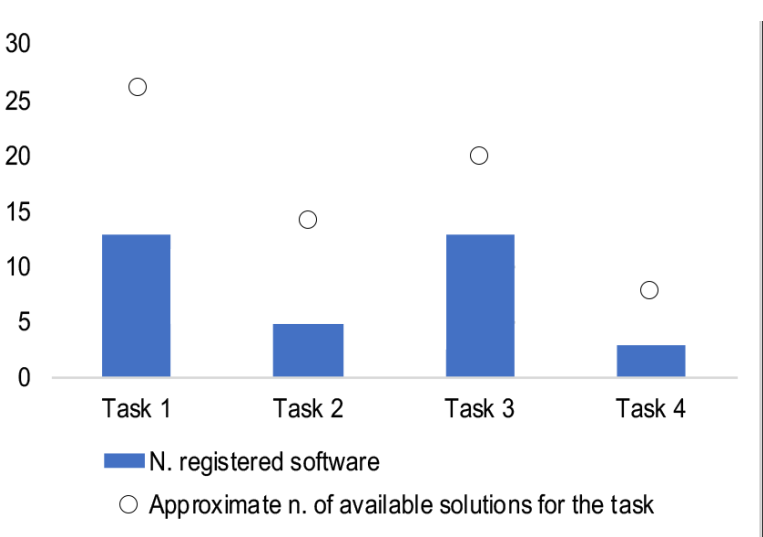

Figure 6. Tools participants declared to test in comparison with the approximated number of solutions as assessed and suggested by the benchmark organisers (different versions are not counted as different software).

\section{INTERIM RESULTS}

The currently submitted results confirm what was already reported by the initial results in Noardo et al (2019), and at this stage we do not have a sufficient number of submissions to perform a more detailed analysis.

\subsection{Interim results for Task 1}

In Task 1, FZK Viewer, FreeCAD, and SketchUP were tested, together with more tests for Revit, which is probably the most used software to work with BIMs. So far, we can confirm the challenges in managing heavy models, as the visualisation of the UpTown.ifc model often causes the software to crash, or it takes a very long time to be imported.

In Revit it is confirmed that the management of the IFC subcategories (e.g. doors subcategories) are nor recognised as they are stored in the exported IFC file.

Also the possibilities to customise the exporting phase in BIM software are few and often do not offer a suitable result.

With the IFCgeometries.ifc dataset, similar problems that were already pointed out were also confirmed again: missing geometries (not read or flattened to the plane), different kinds of curved surfaces interpretation and rendering, different ways to read the geometries heights (e.g. Figure 7). 


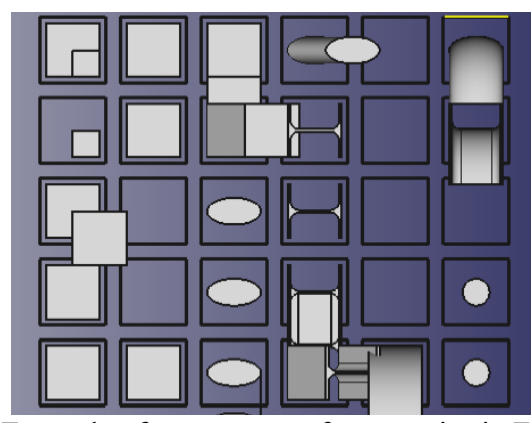

Figure 7. Example of appearance of geometries in FreeCAD.

\subsection{Interim results for Task 2}

There are still too few completed submissions so far to draw any conclusion. It is however possible to understand that probably the georeferencing procedures are being tested and improved before the final submission, which justifies the delay in submitting the results for this task. It may probably require the development of a suitable procedure which might not be already natively implemented in the tested software.

\subsection{Interim results for Task 3}

As for Task 1, many initial results (Noardo et al., 2019) were confirmed for Task 3. For example, Amsterdam.gml takes a lot of time to be imported, and often causes the software to crash before completing the import operation. Also the management of multi-LoD datasets is not easily supported other than by the KIT FZK Viewer. The last general reported problem is related to the management of complex relationships, which can be lost or become even more complex (e.g. new tables) in the conversion and import.

\subsection{Interim results for Task 4}

As with Task 2, despite the interest in registrations, few results were submitted so far, probably because the conversion procedures are still being improved, as it was reported to us by some of the participants, including the meeting on $8^{\text {th }}$ July. The initial submissions that use workflows in the ETL tool FME could report the success in the conversion from IFC to CityGML, but still with the need of some manual or semimanual work to apply the procedure to the specific dataset (e.g. inspecting the geometry in FME Data Inspector, selecting specific elements, etc.). Also in this Task, the conversion of the heaviest dataset is more challenging than with the others.

In both the submitted results so far, the conversion was performed from IFC to CityGML format.

\section{DISCUSSION AND CONCLUSIONS}

This paper presents the ISPRS/EuroSDR GeoBIM Benchmark. This one-year project is investigating the available technical solutions for the integration and interoperability of data using open standards, concerning both 3D geoinformation (CityGML) and 3D building information models (IFC).

The aim of the benchmark is to get a better picture of the state of software support for these two open standards and their integration, in order to formulate recommendations for further development of the standards and the software that implements them.
The paper describes the methodology of the project and presents interim results.

The initial results and most common issues reported for each task (Noardo et al., 2019) were confirmed by the additional results submitted in the last few months.

Although many people still have to submit their test results, it was possible to understand from the feedback we received so far, and from the GeoBIM benchmark (web)meeting, that the interest in contributing to the understanding and description of the available tools to manage standardised data (almost completely on a voluntary base) is high.

In addition, we can already state that different kinds of stakeholders (e.g. researchers, practitioners, software implementers, administrations) find the investigated issue relevant. They are willing to find solutions, which are not very straightforward at the moment, to use standardised and interoperable data in an effective way. Given the bottom-up approach of this project, this was essential for the achievement of the project's aims, among which the wide cross-discipline and cross-expertise collaboration.

Moreover, some people are working on refining their tools (if developers) or their procedures to be tested before delivering the final results, in order to describe the most effective solution they obtained for the given task. Even if this might cause some delays in the delivery of results, it will further push the development of suitable tools to support the use of standardised data.

\section{ACKNOWLEDGEMENTS}

This work was possible thanks to the collaboration of the whole GeoBIM benchmark team (with their work as in-kind contribution to the project), all the data providers, the participants making the tests, listed in the GeoBIM benchmark webpage (https://3d.bk.tudelft.nl/projects/geobimbenchmark/participants.html) and the participants to the GeoBIM benchmark meeting (see meeting results at https://3d.bk.tudelft.nl/projects/geobimbenchmark/events.html).

The benchmark is funded by ISPRS and EuroSDR. This project has also received funding from the European Research Council (ERC) under the European Union's Horizon2020 Research \& Innovation Programme (grant agreement no. 677312 Urban modelling in higher dimensions).

\section{REFERENCES}

Arroyo Ohori, K., Biljecki, F., Diakité, A., Krijnen, T., Ledoux, H., Stoter, J., 2017. Towards an integration of GIS and BIM data: What are the geometric and topological issues. In: ISPRS Annals of Photogrammetry, Remote Sensing \& Spatial Information Sciences, Proceedings of ISPRS 12th Geoinfo Conference, Melbourne, Australia. 26-27.

Bazjanac, V., 2002. Early lessons from deployment of IFC compatible software. In: eWork and eBusiness in Architecture, Engineering and Construction, Proc. fourth Euro. conf. product process modelling, Portorož, SLO, pp. 9-16.

Biljecki, F., Ledoux, H., \& Stoter, J. (2016). Generation of multi-LOD 3D city models in CityGML with the procedural modelling engine Random3Dcity. ISPRS Ann. Photogramm. 
Remote Sens. Spatial Inf. Sci., IV-4/W1, 51-59. http://doi.org/10.5194/isprs-annals-IV-4-W1-51-2016

Biljecki, F., Stoter, J., Ledoux, H., Zlatanova, S., \& Çöltekin, A. (2015). Applications of 3D City Models: State of the Art Review. ISPRS International Journal of Geo-Information, 4(4), 2842-2889.

Ellul, C., Stoter, J., Harrie, L., Shariat, M., Behan, A., Pla, M., 2018. Investigating the state of play of GeoBIM across Europe. In: International Archives of the Photogrammetry, Remote Sensing \& Spatial Information Sciences, 42.

ISO16739:2013. Industry Foundation Classes (IFC) for data sharing in the construction and facility management industries. International Organization for Standardization, March 2013.

Liu, X., Wang, X., Wright, G., Cheng, J., Li, X., Liu, R., 2017. A state-of-the-art review on the integration of Building Information Modeling (BIM) and Geographic Information System (GIS). ISPRS International Journal of GeoInformation, 6(2), 53.

McGlinn, K. R. I. S., Wicaksono, H. E. N. D. R. O., Lawton, W. I. L. L. I. E., Weise, M., Kaklanis, N., Petri, I., \& Tzovaras, D. (2016). Identifying use cases and data requirements for BIM based energy management processes. In CIBSE Technical Symposium.

Noardo, F., Arroyo Ohori, K., Biljecki, F., Krijnen, T., Ellul, C., Harrie, L., Stoter, J., (2019). GeoBIM benchmark 2019: Design and initial results. International Archives of the Photogrammetry, Remote Sensing and Spatial Information Sciences. Proceedings of Geospatial Week, Enschede, 10-14 June, 2019.

Open Geospatial Consortium, 2012. OGC City Geography Markup Language (CityGML) Encoding Standard 2.0.0. Technical report, April 2012.

Sani, M. J., \& Rahman, A. A. (2018). GIS and BIM integration at data level: A review. International Archives of the Photogrammetry, Remote Sensing and Spatial Information Sciences, 42(4/W9).

Wang, H., Pan, Y., \& Luo, X. (2019). Integration of BIM and GIS in sustainable built environment: A review and bibliometric analysis. Automation in Construction, 103, 4152.

Wu, W., Mayo, G., McCuen, T. L., Issa, R. R., \& Smith, D. K. (2018). Building information modeling body of knowledge. II: Consensus building and use cases. Journal of Construction Engineering and Management, 144(8), 04018066.

Zhu, J., Wright, G., Wang, J., Wang, X., 2018. A critical review of the integration of geographic information system and building information modelling at the data level. ISPRS International Journal of Geo-Information, 7(2), 66.

EuroSDR GeoBIM project website, https://3d.bk.tudelft.nl/projects/eurosdr-geobim/ Accessed 08/07/2019.

GeoBIM benchmark 2019 website, https://3d.bk.tudelft.nl/projects/geobim-benchmark/ Accessed 08/07/2019. 